\title{
Intramolecular Sensitization of Photocleavage of the Photolabile 2-(2-Nitrophenyl)propoxycarbonyl (NPPOC) Protecting Group: Photoproducts and Photokinetics of the Release of Nucleosides
}

\author{
Dominik Wöll,*[a, b] Julia Smirnova, ${ }^{[a]}$ Marina Galetskaya, ${ }^{[a]}$ Tamara Prykota, ${ }^{[a]}$ \\ Jochen Bühler, ${ }^{[c]}$ Klaus-Peter Stengele, ${ }^{[c]}$ Wolfgang Pfleiderer, ${ }^{[a]}$ and Ulrich E. Steiner*[a]
}

\begin{abstract}
Novel photolabile protecting groups based on the 2-(2-nitrophenyl)propoxycarbonyl (NPPOC) group with a covalently linked thioxanthone as an intramolecular triplet sensitizer exhibit significantly enhanced light sensitivity under continuous illumination. Herein we present a detailed study of the photokinetics and photoproducts of nucleosides caged with these new protecting groups. Relative to the parent NPPOC group, the light sensitivity of
\end{abstract}

the new photolabile protecting groups is enhanced by up to a factor of 21 at $366 \mathrm{~nm}$ and is still quite high at $405 \mathrm{~nm}$, the wavelength at which the sensitivity of the parent compound is practically zero. A new pathway for deprotection of the NPPOC group pro-

Keywords: DNA chips • energy transfer $\cdot$ photochemistry $\cdot$ protecting groups $\cdot$ sensitization ceeding through a nitroso benzylalcohol intermediate has been discovered to complement the main mechanism, which involves $\beta$ elimination. Under standard conditions of lithographic DNA-chip synthesis, some of the new compounds, while maintaining the same chip quality, react ten times faster than the unmodified NPPOCprotected nucleosides.

\section{Introduction}

Blocking of functional groups by protecting groups and their deblocking under chemically selective conditions is a key technique in organic, particularly in bioorganic, synthesis. $^{[1]}$ A special advantage of photolabile protecting groups $^{[2,3]}$ results from their specific photochemical reactivity that can be triggered by the absorption of light and makes them "orthogonal" [4] to many other chemical cleav-

[a] Dr. D. Wöll, Dr. J. Smirnova, M. Galetskaya, Dr. T. Prykota, Prof. Dr. W. Pfleiderer, Prof. Dr. U. E. Steiner

Fachbereich Chemie, Universität Konstanz

Universitätsstraße 10, 78457 Konstanz (Germany)

Fax: (+49) 7531-88-3014

E-mail: dominik.woell@uni-konstanz.de ulrich.steiner@uni-konstanz.de

[b] Dr. D. Wöll

Present address: Laboratory for Photochemistry and Spectroscopy Katholieke Universiteit Leuven, Celestijnenlaan 200F 3001 Heverlee (Belgium)

[c] Dr. J. Bühler, Dr. K.-P. Stengele NimbleGen Systems GmbH, Beuthener Str. 2 84478 Waldkraiburg (Germany) age conditions. Even a "photoorthogonality" of photolabile protecting groups based on their distinction by the wavelength of the actinic light has been demonstrated. ${ }^{[5]}$ Because light-induced reactions are usually very fast, photocleavage by using short light pulses can be achieved on a short timescale and the release of the previously "caged" compounds can be exploited in many ways, for example, as phototriggers for biokinetic studies. ${ }^{[6-8]}$ Furthermore, the exposure to light can be spatially controlled. This is a prerequisite, for example, in the synthesis of high-density DNA chips ${ }^{[9,10]}$ in which many oligonucleotides of different base sequences are immobilized on a glass substrate in arrays of up to one million spots per square centimeter. With such chips, huge amounts of genetic information become amenable to massive parallel detection. ${ }^{[1-14]}$

Photolabile protecting groups used for DNA-chip synthesis should be removable in high yields, that is, have a low tendency for side reactions to avoid errors in the oligonucleotide sequence. Furthermore, they should exhibit high light sensitivity to reduce the probability of light-induced damage of the chip and to keep the overall processing time within economic limits. The light sensitivity is determined by the product of two factors, the quantum yield $(\phi)$ of the cleavage reaction and the absorption coefficient $(\varepsilon)$ at the 
wavelength of irradiation. An overview of photoremovable protecting groups used in DNA-chip synthesis has been given in a review by Pirrung and Rana. ${ }^{[6]}$ Clearly, compounds with an $o$-nitrophenylalkyl function play a dominant role. Currently, the methylnitropiperonyloxycarbonyl (MeNPOC) group seems to be used most. ${ }^{[15,16]}$ It is of the $o$ nitrobenzyl-type in which cleavage occurs at the benzylic carbon and the leaving moiety is an aromatic $o$-nitrosocarbonyl compound. ${ }^{[17]}$ In photoremovable protecting groups involving the 2-(2-nitrophenyl)propoxycarbonyl (NPPOC) group, which was introduced by Pfleiderer and co-workers, ${ }^{[18-20]}$ cleavage is due to $\beta$ elimination, and formation of the reactive and problematic nitroso byproduct ${ }^{[21]}$ can be suppressed by using suitable reaction conditions (Scheme 1). ${ }^{[22]}$ This is probably the reason why chips of higher quality result when using the NPPOC group. ${ }^{[23,24]}$

At $366 \mathrm{~nm}$, the most commonly used mercury line for irradiation, the light sensitivities $\varepsilon \phi$ of MeNPOC $\left(\varepsilon_{366 \mathrm{~nm}, \mathrm{MeOH}}=\right.$ $\left.3000 \mathrm{M}^{-1} \mathrm{~cm}^{-1}, \quad \phi_{\mathrm{MeOH}}=0.03\right)$ and NPPOC $\left(\varepsilon_{366 \mathrm{~nm}, \mathrm{MeOH}}=\right.$ $\left.250 \mathrm{M}^{-1} \mathrm{~cm}^{-1}, \phi_{\mathrm{MeOH}}=0.41\right)$ are very similar. However, it is of interest to note that the large gain in $\varepsilon$ caused by the substitution of the aromatic ring in MeNPOC is completely compensated for by a concomitant decrease in the quantum yield, which indicates a loss of reactivity of the nitro group in the lowest photoexcited state as a consequence of the increased $\pi$-electron density in the aromatic ring. In NPPOC, the quantum yield is high, but the light sensitivity is limited by the low value of $\varepsilon$. To avoid any compensating effect between $\varepsilon$ and $\phi$ when trying to improve the performance of NPPOC, we chose sensitization as a way to separate the process of light absorption from the photochemical reaction, so that both properties could be independently optimized. Thioxanthone turned out to be the most suitable sensitizer for the NPPOC group. It has been shown that intermolecular sensitization works well in homogeneous solution and on a chip surface, and that under either conditions the kinetics can be quantitatively modeled. ${ }^{[25]}$

When using free sensitizer molecules, diffusion-controlled encounters between the photoexcited sensitizer and the photoreactive chromophore have to occur during the lifetime of the excited sensitizer and each photoreactive chromophore has to find an excited sensitizer. These requirements essentially limit the efficiency of the process. Therefore, we choose to covalently link the two partners such that the sensitizer moiety can function as an intramolecular antenna for the photoreactive moiety. ${ }^{[26]}$ The enhancement of photolysis of a photolabile protecting group by a covalently linked antenna molecule has been reported by Papageorgiou and coworkers $^{[27,28]}$ and our own group. The syntheses of the compounds shown in Scheme 2 are described in reference [29]. The letter/number code for these compounds is of the general structure TmLn-OR. The first letter indicates the antenna moiety ( $\mathrm{T}$ for thioxanthone), the number $m$ gives the position on the NPPOC moiety at which the linker is attached (16 for the aromatic positions, 7 for the benzylic position), the letter L characterizes the type of chain that links NPPOC and the sensitizer (S: saturated carbon chain, D: single bond carbon chain including one double bond, $\mathrm{T}$ : single bond carbon chain including one triple bond, E: ester bridge), the number $n$ is the length of the chain connecting the aromatic rings of NPPOC and thioxanthone, and throughout this paper, the protected moiety $(\mathrm{R})$ is a nucleoside connected to NPPOC by a carbonate linker. A preliminary account of the properties of these compounds has appeared. ${ }^{[30]}$ Furthermore, a detailed spectroscopic study of

Scheme 1. Principal cleavage pathways and products of NPPOC-protected substrates. 


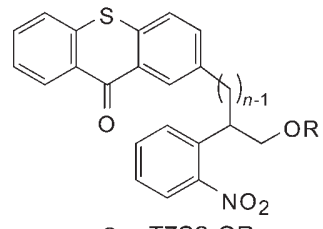

$n=2:$ T7S2-OR

$n=3:$ T7S3-OR

$n=4:$ T7S4-OR

$n=5:$ T7S5-OR

$n=6:$ T7S6-OR

$n=9:$ T7S9-OR<smiles>[R]OCC(C)c1cc(-c2ccc3sc4ccccc4c(=O)c3c2)ccc1[N+](=O)[O-]</smiles>
T5SO-OR

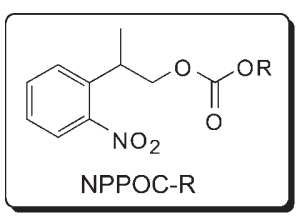<smiles>[R]OCC(C)c1ccc(C(=O)Oc2ccc3sc4ccccc4c(=O)c3c2)cc1[N+](=O)[O-]</smiles><smiles>[R]OCC(C/C=C/c1ccc2sc3ccccc3c(=O)c2c1)c1ccccc1[N+](=O)[O-]</smiles><smiles>[R]OCC(CC#Cc1ccc2sc3ccccc3c(=O)c2c1)c1ccccc1[N+](=O)[O-]</smiles>

T7T4-OR<smiles>CC(=O)OCC1OC2CC(n3cc(C)c(=O)[nH]c3=O)C1O2</smiles>

$\mathrm{R}=$ (CO)Thy<smiles>CC(=O)Nc1ccn(C2CC3COC(=O)OCC(C3)O2)c(=O)n1</smiles>

(CO)Cyt ${ }^{A c}$

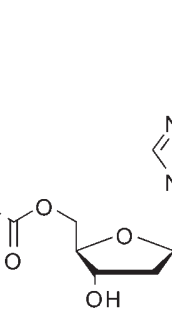

(CO)Ade ${ }^{\mathrm{Bz}}$

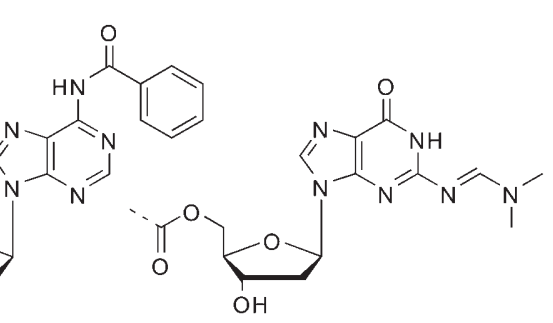

(CO)Gua ${ }^{A m}$

Scheme 2. NPPOC-conjugates investigated in this work.

the mechanism of sensitization that led to new insights into the photophysics of thioxanthone has also been published. ${ }^{[31]}$ Herein, the photokinetics and photoproduct formation of the new compounds under continuous irradiation are described in detail.

\section{Results and Discussion}

The compounds investigated in this work are shown in Scheme 2. Their synthesis and spectroscopic properties are described elsewhere. ${ }^{[29,31]}$

Products after continuous irradiation: For the characterization of the light sensitivity of the new compounds and the distribution of photoproducts, continuous irradiation experiments were carried out with deaerated solutions in methanol by using the lines at 366 and $405 \mathrm{~nm}$, respectively, of a mercury high-pressure light source. At $405 \mathrm{~nm}$, the absorption of the photolabile NPPOC group is practically negligible. Hence, photoreactions observed at this wavelength are almost exclusively due to the sensitization effect of the thioxanthone antenna. The reaction progress was followed by HPLC analyses after suitable irradiation periods (see the Supporting Information). As an example, in Figure 1 we present the results for the irradiation of T7S4-O(CO)Thy at $366 \mathrm{~nm}$. As in previous experiments with NPPOC and free thioxanthone as the sensitizer, ${ }^{[25]}$ we observe the decay of the peak of the initial protected thymidine $\left(t_{\mathrm{R}}=17.3 \mathrm{~min}\right)$ and a concomitant rise of the peak of free thymidine $\left(t_{\mathrm{R}}=6.6 \mathrm{~min}\right)$. The peak at
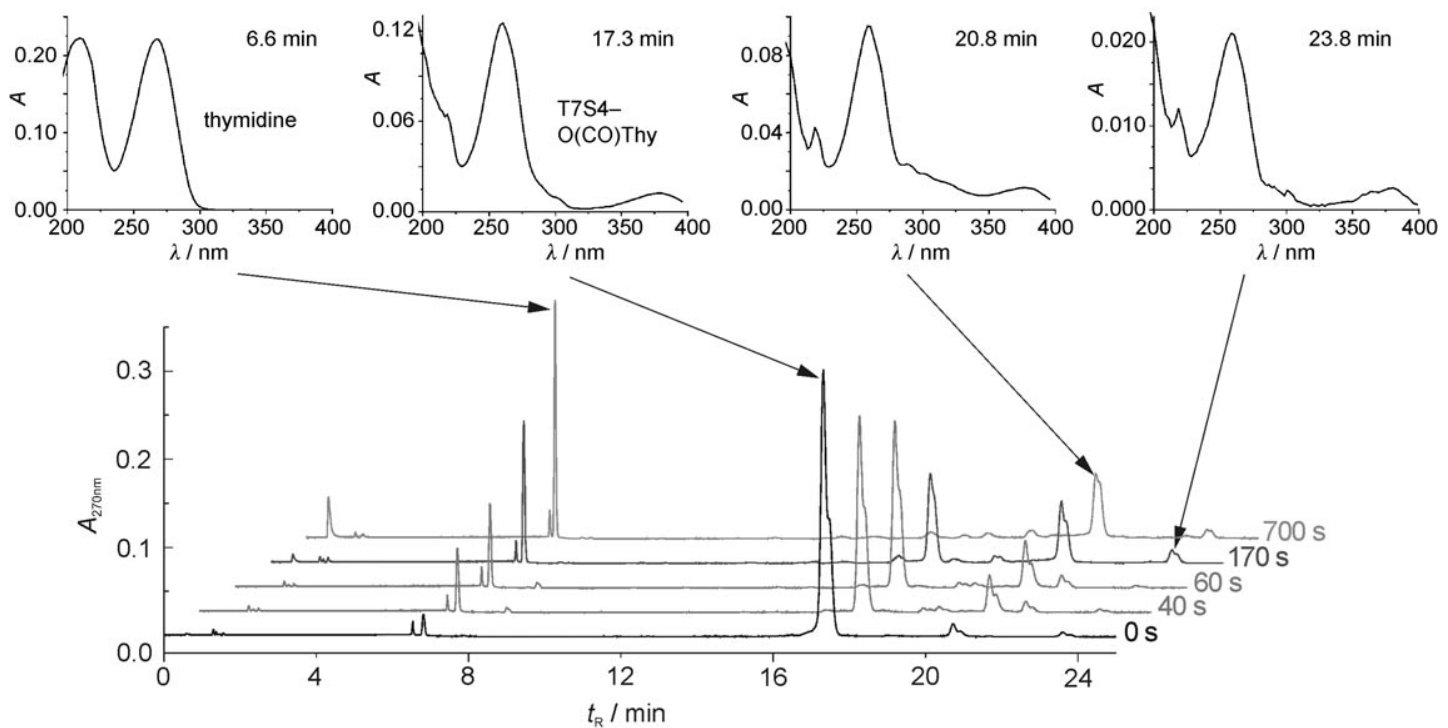

Figure 1. HPLC chromatograms representing the photoproduct distribution after irradiating T7S4-O(CO)Thy $(0.117 \mathrm{~mm})$ in deaerated MeOH for the times indicated at each trace. Irradiation wavelength $=366 \mathrm{~nm}, I_{0}=1.75 \times 10^{-8}$ einstein $\mathrm{cm}^{-2} \mathrm{~s}^{-1}$. 
$t_{\mathrm{R}}=23.8 \mathrm{~min}$ is assigned to the styrene derivative from the $\beta$-elimination reaction (styrene product in Scheme 1). As observed previously, this peak decreases at longer irradiation times due to subsequent transformations of this product. ${ }^{[22,25,32]}$ The peak at $t_{\mathrm{R}}=20.8 \mathrm{~min}$ is assigned to a nitroso product that originates from the primary aci-nitro intermediate by a reaction pathway competing with $\beta$ elimination (Scheme 1). ${ }^{[22]}$ This pathway primarily results in formation of a nitroso product (nitroso product 1 in Scheme 1). As a detailed structural analysis has shown, an intramolecular rearrangement induced by the electrophilic attack of the newly formed benzylic $\mathrm{OH}$ group at the carbon center of the carbonate linker gives rise to nitroso product 2 (see Scheme 1). Whether the latter reaction occurs, and to what extent, depends on the solvent. It could be shown that in acetonitrile the irradiation of $\mathrm{T} 7 \mathrm{~S} 4-\mathrm{O}(\mathrm{CO})$ Thy results mainly in the formation of nitroso product 1 (peak at $t_{\mathrm{R}}=$ 16.4 min in Figure S4 in the Supporting Information), whereas in methanol nitroso product 2 is formed (peak at $t_{\mathrm{R}}=$ 20.8 min in Figure 1).

The five species in Scheme 1 (protected nucleoside, free nucleoside, styrene derivative, nitroso product 1, nitroso product 2) are sufficient to account for the essential features of the photochemical product distribution for all compounds investigated except for T7D4 and T7T4 in which a double or a triple bond, respectively, is present in the linker chain; these compounds will be discussed in further detail below.

Photokinetic analysis, yields, quantum yields, and light sensitivity: The disappearance of the starting material upon irradiation gives a qualitative impression of the light sensitivity of the compounds investigated. Pertinent photokinetic curves for irradiation at 366 and $405 \mathrm{~nm}$ are shown in Figure 2.

In comparison with the parent NPPOC compound it is evident that an enormous enhancement of the light sensitivity is achieved through the intramolecular attachment of a thioxanthone antenna. Even at $405 \mathrm{~nm}$, the wavelength at which the NPPOC compounds are not photosensitive at all (curve not shown), the new thioxanthone/NPPOC conjugates show high sensitivity.

The photokinetic data were analyzed according to the rate law given as Equation (1):

$\frac{\mathrm{d} c}{\mathrm{~d} t}=-I_{0} \frac{F d}{V} \frac{\left(1-10^{-A(t)}\right)}{A(t)} \varepsilon c(t) \phi$

in which $I_{0}$ represents the photon irradiance, $F$ is the illuminated cross section, $d$ is the optical path length, $V$ is the volume of the solution, $A(t)$ is the absorbance of the solution after irradiation time $t, \varepsilon$ is the molar absorption coefficient of the starting compound, $c$ is its concentration, and $\phi$ is the sum of the quantum yields of all photoreactions involving the NPPOC chromophore. The quantum yield $(\phi)$ was determined by fitting the result of the numerical integration of Equation (1) to the observed time dependence of $c(t)$ (Figure 2). The simulated curve for concentration $c(t)$ of
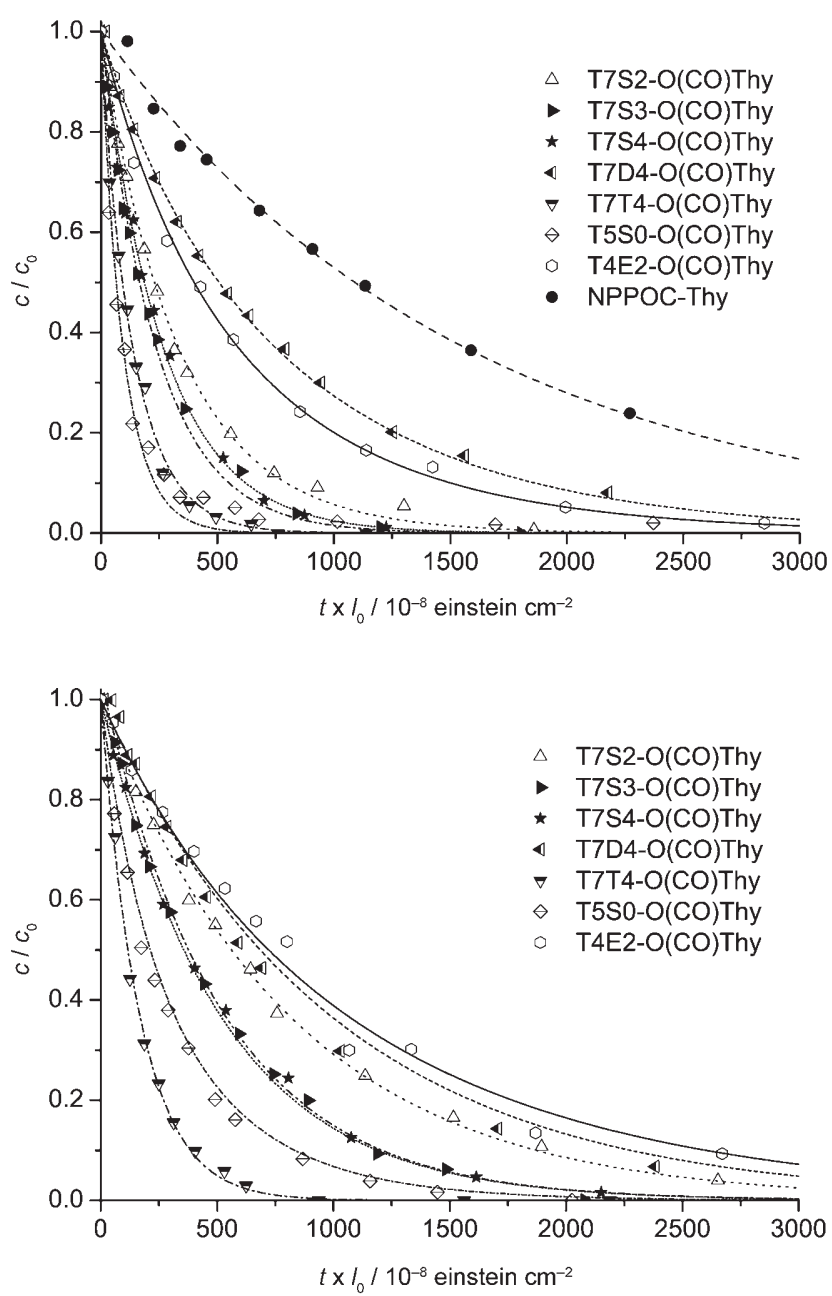

Figure 2. Decay kinetics of thioxanthone/NPPOC-protected thymidine under continuous irradiation at 366 (top) and $405 \mathrm{~nm}$ (bottom). For better comparability of the kinetic curves measured at different irradiation light intensities, the remaining fraction of starting material is plotted against the dose of light $t \times I_{0}$. The lines shown represent kinetic fits according to Equation (1). Within the light-dosage range shown, no significant reaction was observed for NPPOC-Thy at $405 \mathrm{~nm}$.

the starting material was also used to extrapolate the HPLC data points for the concentration of deprotected thymidine to infinite irradiation time. The evaluated quantum yields $(\phi)$ and nucleoside deprotection yields $\left(Y_{\text {Nucl }}\right)$ are listed in Table 1 . We also quote the values of the product $\varepsilon \phi$, which is the appropriate value of merit for comparing the light sensitivities of the various compounds.

By comparing the values of $\varepsilon \phi$ as the benchmark figures of light sensitivity for the antenna bearing new compounds with the values for the unsensitized reaction of NPPOCThy, it is clear that a considerable enhancement is achieved by intramolecular sensitization. For irradiation at $366 \mathrm{~nm}$, a maximum enhancement factor of 21 is achieved with T5S0$\mathrm{O}(\mathrm{CO})$ Thy. For irradiation at $405 \mathrm{~nm}$, where the sensitivity of the parent NPPOC compound is almost zero, somewhat lower sensitivities than at $366 \mathrm{~nm}$, but still higher than for NPPOC at $366 \mathrm{~nm}$, are achieved. This is particularly useful 
Table 1. Quantum yields $(\phi)$, light sensitivities $(\varepsilon \phi)$, and nucleoside yields $\left(Y_{\text {Nucl }}\right)$ of protected nucleosides for irradiation in deaerated methanol.

\begin{tabular}{|c|c|c|c|c|c|c|}
\hline \multirow[b]{2}{*}{ Compound } & \multicolumn{3}{|c|}{ Irradiation at $366 \mathrm{~nm}$} & \multicolumn{3}{|c|}{ Irradiation at $405 \mathrm{~nm}$} \\
\hline & $\phi$ & $\varepsilon \phi^{[\mathrm{a}]}$ & $Y_{\text {Nucl }}$ & $\phi$ & $\varepsilon \phi^{[\mathrm{a}]}$ & $Y_{\text {Nucl }}$ \\
\hline NPPOC-Thy & 0.41 & 100 & 0.90 & 0.41 & 7 & \\
\hline T7S2-O(CO)Thy & 0.18 & 690 & 0.60 & 0.09 & 160 & 0.63 \\
\hline T7S3-O(CO)Thy & 0.21 & 820 & 0.75 & 0.14 & 320 & 0.79 \\
\hline T7S4-O(CO)Thy & 0.21 & 800 & 0.86 & 0.14 & 320 & 0.75 \\
\hline T7D4-O(CO)Thy & 0.08 & 250 & 0.27 & 0.05 & 170 & 0.38 \\
\hline T7T4-O(CO)Thy & 0.42 & 1500 & 0.21 & 0.38 & 1000 & 0.33 \\
\hline T4E2-O(CO)Thy & 0.09 & 360 & 0.92 & 0.09 & 160 & 0.82 \\
\hline T7S0-O(CO)Thy & 0.26 & 2100 & 0.66 & 0.27 & 650 & 0.89 \\
\hline $\mathrm{T} 7 \mathrm{~S} 0-\mathrm{O}(\mathrm{CO}) \mathrm{Cyt}^{\mathrm{Ac}}$ & 0.29 & 2400 & 0.61 & 0.23 & 580 & 0.63 \\
\hline T7S0-O(CO)Ade ${ }^{B z}$ & 0.36 & 2900 & 0.52 & 0.24 & 580 & 0.54 \\
\hline T7S0-O(CO)Gua ${ }^{\mathrm{Am}}$ & 0.11 & 920 & 0.52 & 0.06 & 160 & 0.64 \\
\hline
\end{tabular}

[a] in $\mathrm{m}^{-1} \mathrm{~cm}^{-1}$

because diode lasers at this wavelength have become commercially available.

Whereas the increase in $\varepsilon$ is the determining factor in the sensitivity gain by the introduction of an antenna molecule, a general decrease in the photochemical quantum yield could not be avoided, but was kept within a modest range of about a factor of $1 / 2$ relative to direct excitation of NPPOC. (T7D4-OR and T7T4-OR should not be considered because other photochemical primary reactions, which do not lead to a release of the protected substrate, must also be taken into account; see below). It is not yet clear, whether the reduction in quantum yield is due to a lower efficiency of formation of the aci-nitro intermediate or to an increased reversibility of the formation of this species. This question must be left open for further studies. The photochemical quantum yields are fairly independent of the excitation wavelength except for compounds $\mathrm{T} 7 \mathrm{~S} n-\mathrm{O}(\mathrm{CO})$ Thy with short aliphatic linkers ( $n=2$ to 4 ), for which a drop by a factor of $1 / 2$ is observed between 366 and $405 \mathrm{~nm}$.

For practical purposes, the total yield of release of deprotected substrate is at least as important as the light sensitivity. With the new compounds, these yields are between 52 and $92 \%$. It should be noted, however, that under reaction conditions for the synthesis of DNA chips, the yields can be different and, of course, reaction conditions can be further optimized for maximizing this quantity. For example, the yield of thymidine release from NPPOC protected thymidines has been reported to be as high as $98 \%$ on a chip, ${ }^{[25]}$ whereas under the conditions of our experiments the yield is only $90 \%$.

Experiments with other nucleosides: Thymidine has served as the standard nucleoside for most of our investigations. To demonstrate the principal suitability of the new type of antenna bearing protecting groups, the T7S0 conjugates were also synthesized for deoxyadenosine, deoxycytidine, and deoxyguanosine, which also have a further protecting group at their amino position (for structures, see Scheme 2). The products formed after irradiation were similar for all nucleosides (see Figures S8-S11 in the Supporting Information). The structures of the four main products are assigned to the HPLC chromatograms: the free nucleoside at retention times of approximately $8 \mathrm{~min}$, nitroso product 1 at retention times slightly earlier than the protected nucleosides, nitroso product 2 at approximately $21 \mathrm{~min}$, and the styrene product at approximately $24 \mathrm{~min}$. Because nitroso product 2 and the styrene product are independent of the initial protected nucleoside, their UV-visible spectra are identical in all cases. In contrast, the UV-visible spectrum of nitroso product 1 shows a signature of the investigated nucleoside.

The light sensitivity of protected deoxyguanosine amidite is less than half of the value of the other protected nucleosides, as shown in Figure 3 and Table 1. The reason for this

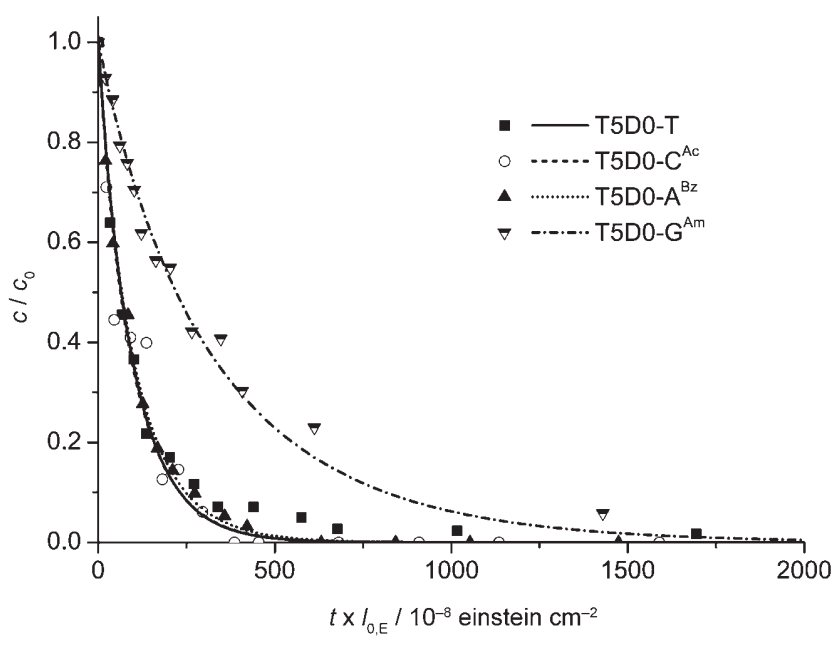

Figure 3. Decay kinetics of thioxanthone/NPPOC-protected nucleosides under continuous irradiation at $366 \mathrm{~nm}$. The lines represent kinetic fits according to Equation (1).

is a decrease in the deprotection quantum yield due to competing electron transfer from the deoxyguanosine to the thioxanthone moiety. This electron transfer is reversible and results in a recovery of the reactants. Experiments for intermolecular quenching of thioxanthone by deoxyguanosine amidite gave a bimolecular rate constant of $2.3 \times 10^{9} \mathrm{M}^{-1} \mathrm{~s}^{-1}$ (see the Supporting Information).

Due to the reduced quantum efficiency for the deprotection of deoxyguanosine amidite, the gain in light sensitivity when using the new photolabile protecting groups is less pronounced than for the other nucleosides. However, we believe that by using a different protecting group for the guanine amino function, the oxidation potential of the nucleoside could be reduced and thus, electron transfer would be avoided or at least reduced in its efficiency.

Photokinetics of the T7D4-group: In the case of the T7D4 group, energy transfer to the NPPOC chromophore and subsequent photorelease of the substrate has to compete with a very efficient photochemical trans/cis isomerization. The situation is described in Scheme 3.

The time profiles of the species observed when irradiating T7D4-O(CO)Thy is shown in Figure 4. 


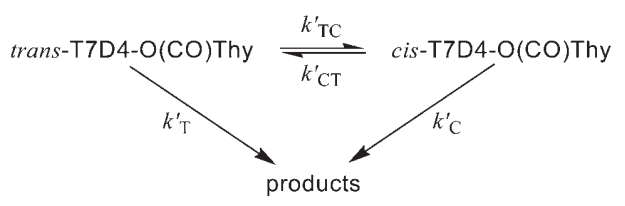

Scheme 3. Photoisomerization and photoreaction of trans- and cis-T7D4$\mathrm{O}(\mathrm{CO})$ Thy.

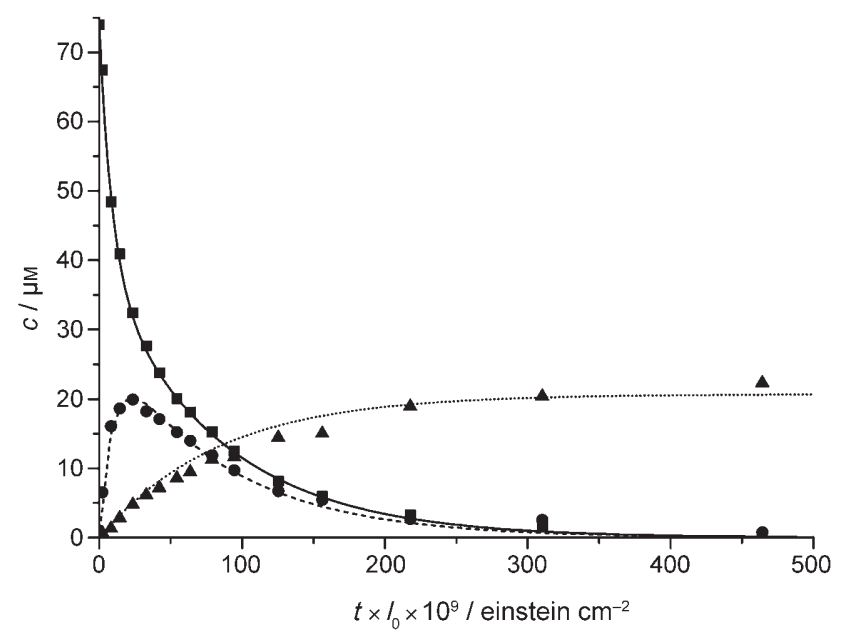

Figure 4. HPLC-derived concentrations of trans-T7D4-O(CO)Thy ( $\mathbf{m})$, cis-T7D4-O(CO)Thy $(\bullet)$, and thymidine $(\boldsymbol{\wedge})$ during irradiation at $366 \mathrm{~nm}$ in deaerated $\mathrm{MeOH}$.

The kinetics of the observed compounds can be modeled by differential Equations (2) to (4) :

$\frac{\mathrm{d}[\text { trans }]}{\mathrm{d} E_{h v}}=-k_{\mathrm{T}}^{\prime}[$ trans $]-k_{\mathrm{TC}}^{\prime}[$ trans $]+k_{\mathrm{CT}}^{\prime}[$ cis $]$

$\frac{\mathrm{d}[c i s]}{\mathrm{d} E_{h v}}=k_{\mathrm{TC}}^{\prime}[\operatorname{trans}]-k_{\mathrm{CT}}^{\prime}[c i s]-k_{\mathrm{C}}^{\prime}[c i s]$

$\frac{\mathrm{d}[\text { Thymidine }]}{\mathrm{d} E_{h v}}=\left(k_{\mathrm{T}}^{\prime}[\right.$ trans $]+k_{\mathrm{C}}^{\prime}[$ cis $\left.]\right) \eta_{\text {Thymidine }}$

in which [trans], $[$ cis], and [Thymidine] are the concentrations of the compounds indicated, $E_{h v}$ is the dose of light [einstein $\mathrm{cm}^{-2}$ ], and $\eta_{\text {Thymidine }}$ is the efficiency of thymidine release after population of the NPPOC triplet. The effective rate constants are related to the pertinent light sensitivity figures $\varepsilon \phi$ of the corresponding processes, an example of which is given in Equation (5) (see Scheme 3).

$k_{\mathrm{T}}^{\prime}=\frac{F d}{V} \ln 10 \varepsilon_{\text {trans }} \phi_{\mathrm{T}}=0.7675 \varepsilon_{\text {trans }} \phi_{\mathrm{T}}$

in which $F$ is the illuminated area, $d$ is the thickness of the cuvette, $V$ is the illuminated volume, $\varepsilon_{\text {trans }}$ is the absorption coefficient of the trans isomer, and $\phi_{\mathrm{T}}$ is the quantum yield of sensitized NPPOC triplet formation of the trans isomer. The definitions of $k_{\mathrm{C}}^{\prime}, k_{\mathrm{TC}}^{\prime}$, and $k_{\mathrm{CT}}^{\prime}$ are analogous.

The light sensitivity figures for these processes are given in Table 2. The values confirm that the isomerization be-

Table 2. Light sensitivity values $(\varepsilon \phi)$ for the processes of T7D4 shown in Scheme 3 for irradiation in $\mathrm{MeOH}$ at 366 or $405 \mathrm{~nm}$, respectively.

\begin{tabular}{lllll}
\hline & $\begin{array}{l}\varepsilon_{\text {trans }} \phi_{\mathrm{TC}} \\
{\left[\mathrm{M}^{-1} \mathrm{~cm}^{-1}\right]}\end{array}$ & $\begin{array}{l}\varepsilon_{\text {cis }} \phi_{\mathrm{CT}} \\
{\left[\mathrm{M}^{-1} \mathrm{~cm}^{-1}\right]}\end{array}$ & $\begin{array}{l}\varepsilon_{\text {trans }} \phi_{\mathrm{T}} \\
{\left[\mathrm{M}^{-1} \mathrm{~cm}^{-1}\right]}\end{array}$ & $\begin{array}{l}\varepsilon_{\text {cis }} \phi_{\mathrm{C}} \\
{\left[\mathrm{M}^{-1} \mathrm{~cm}^{-1}\right]}\end{array}$ \\
\hline $\begin{array}{l}366 \mathrm{~nm} \\
\text { deaerated }\end{array}$ & 630 & 620 & 130 & 170 \\
$\begin{array}{l}366 \mathrm{~nm} \\
\text { aerated }\end{array}$ & 680 & 760 & 170 & 150 \\
$\begin{array}{l}405 \mathrm{~nm} \\
\text { deaerated }\end{array}$ & 420 & 440 & 110 & 110 \\
\hline
\end{tabular}

tween the trans and cis form is more efficient than the release of thymidine. Therefore, the photostationary equilibrium between the trans and cis form of T7D4-O(CO)Thy is reached before most of the substrate has been deprotected, and the quantum yield of release is decreased by a factor of around three relative to T7S4-O(CO)Thy, which is the corresponding compound with a saturated linker.

Photochemistry of the T7T4-group: In case of the T7T4group, the triple bond gives rise to the formation of an isomer, $\mathrm{T} 7 \mathrm{~T} 4 \rightarrow \mathrm{P} 2$, of the starting compound, presumably through the cycloaddition product, $\mathrm{T} 7 \mathrm{~T} 4 \rightarrow \mathrm{P} 1$, as represented in Scheme 4 (see the Supporting Information for details of the structural assignment of compound $\mathrm{T} 7 \mathrm{~T} 4 \rightarrow \mathrm{P} 2$ ).

Chip experiments: In preliminary experiments, the new photolabile protecting groups were also tested under conditions for real chip production. For the synthesis of an oligothymidine test chip (Figure 5), the protected thymidines were converted into their corresponding phosphoramidites by established procedures. ${ }^{[33]}$ The stepwise yield for extend-

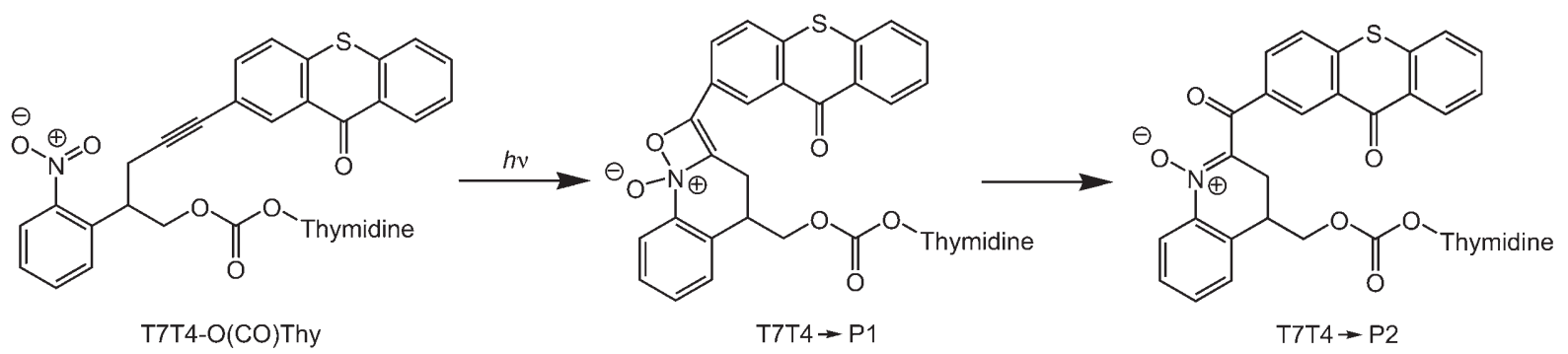

Scheme 4. Dominant photochemical reaction pathway for T7T4-O(CO)Thy. 

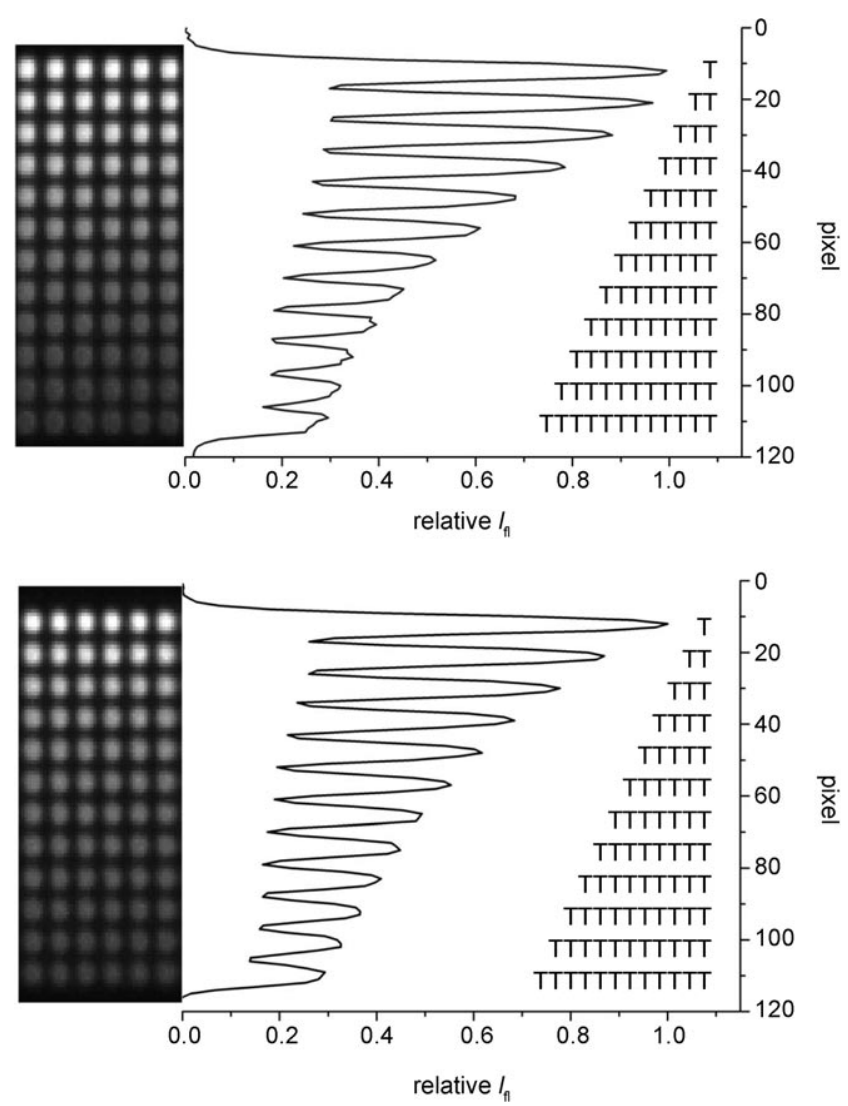

Figure 5. Synthesis of oligothymidines (1-12 nucleotides when going from the top to the bottom) on a chip with the new protecting groups $\mathrm{T} 7 \mathrm{~S} 4$ (top) and T7S0 (bottom), as described in reference [15]. After final deprotection, the free $\mathrm{OH}$ groups on each spot are treated with the fluorescence label reagent Cy3-amidite. A section of the chip produced is shown together with the fluorescence intensity along one vertical line of spots. The irradiation time per cycle was approximately $5 \mathrm{~s}$ in DMSO. T indicates the number of thymidines in the oligothymidine chains produced.

ing the oligonucleotide chain by one thymidine was determined by using the fluorescence labeling method described in references [15] and [25]. In summary, a series of features composed of oligonucleotides of different length ranging from one to twelve bases was grown by employing the corresponding number of illumination and reaction cycles. After synthesis of the oligonucleotides, all of the features were deprotected, and $\mathrm{Cy} 3$-amidite was coupled to the terminal hydroxyl groups. The resulting fluorescence image represents a relative measure of the remaining hydroxyl groups.

The irradiation times are approximately ten times shorter than those usually applied for NPPOC. In both cases, T7S4 (Figure 5, top) and T7S0 (Figure 5, bottom), a yield of approximately $90 \%$ was obtained. Conditions were not optimized, but we believe that with optimization almost quantitative yields are possible. This is underlined by the fact that no significant changes in quality or yields were observed in comparable experiments with the commercial NPPOC group.

\section{Conclusion}

A novel class of photoremovable protecting groups based on the NPPOC group enhanced by a thioxanthone chromophore covalently linked as an intramolecular antenna has been presented. Although the quantum yield of the photocleavage of NPPOC is somewhat smaller in the thioxanthon/ NPPOC conjugates, the light sensitivity of the new complexes, as indicated by $\varepsilon \phi$, is significantly higher. Enhancement factors of about 20 at $366 \mathrm{~nm}$ and about 140 at $405 \mathrm{~nm}$ have been observed. Unless there are other photoreactive functions, such as those introduced by the linkers with double or triple bonds, the yield of photorelease of the caged substrate is high $(52-92 \%)$. The new protecting groups react via the intermediates known from unsensitized NPPOC photochemistry to give nitrostyrene and/or nitrosobenzene derivatives. As shown in this work for the first time, however, the nitroso product can continue reacting. It undergoes an intramolecular re-esterification, which results in deprotection of the nucleoside. All four nucleosides show similar chemical yields and products. However, the gain in light sensitivity for deoxyguanosine amidite is less due to thioxanthone triplet quenching by intramolecular reversible electron transfer from the nucleoside.

The new protecting groups were tested under standard conditions of photolithographic DNA-chip synthesis. Similar chip quality as those produced with NPPOC could be achieved in 10-fold shorter irradiation times.

Finally, it is worth noting that the photosensitivity of the new compounds is only slightly affected by the presence of oxygen because of the short triplet lifetime of the thioxanthone moiety in the proximity of the NPPOC chromophore. For practical applications, this represents another advantage because the reaction systems need not be operated under air-free conditions. In conclusion, it has been shown that intramolecular sensitization is an efficient strategy for improving the light sensitivity of photolabile protecting groups. This is of particular interest in applications in which, for scientific or economic reasons, short irradiation times are essential.

\section{Experimental Section}

NMR and MS spectra: NMR spectra were measured with a JEOL GX 400 FT-NMR or a Bruker DRX 600 spectrometer. EI and FAB mass spectra were recorded with a Varian MAT 312 mass spectrometer. The FAB ion source was from AMD.

Continuous irradiation in solution: A high-pressure mercury lamp (Osram HBO 200) was used. The light was passed through a heat filter (optical length $5 \mathrm{~cm}$, filled with a saturated aqueous solution of $\mathrm{CuSO}_{4}$ ), a collimating lens, an electronic shutter, a $366 \mathrm{~nm}$ interference filter (Schott), and a thermostated optical cell holder with a cell of $1 \mathrm{~cm}$ path length (Hellma QS) equipped with a magnetic stirrer bar. The light flux was determined by azobenzene actinometry. ${ }^{[34]}$ Typical values were around $3 \times 10^{-8}$ einstein $\mathrm{cm}^{-2} \mathrm{~s}^{-1}$. The cell was filled with the probe solutions $(3 \mathrm{~mL})$ and sealed by a rubber septum. It was purged with nitrogen for $15 \mathrm{~min}$ and irradiated for fixed intervals of time. UV/Vis absorption 
spectra were recorded before and after irradiation. Reactants and products were separated and quantified by HPLC.

HPLC: HPLC measurements were carried out on a Merck-Hitachi HPLC system, including a LiChrospher $100 \mathrm{RP}-18(5 \mu \mathrm{m})$ column, a L7100 pump, a L-7200 autosampler, a L-7450A UV diode array detector, and a L-7000 interface by using the "HSM-manager" software. A gradient from pure water to pure acetonitrile was used.

\section{Acknowledgements}

This work was carried out within Research Unit 434 (Oligosaccharide and DNA chips-recognition of secondary gene products) funded by the Deutsche Forschungsgesellschaft (DFG Ste 283/7).

[1] T. W. Greene, P. G. M. Wuts, Protective Groups in Organic Synthesis, Wiley, New York, 1999.

[2] C. G. Bochet, J. Chem. Soc. Perkin Trans. 1 2002, 125-142.

[3] A. P. Pelliccioli, J. Wirz, Photochem. Photobiol. Sci. 2002, 1, 441458.

[4] R. B. Merrifield, G. Barany, W. L. Cosand, M. Engelhard, S. Mojsov, Pept. Proc. Am. Pept. Symp. 5th 1977, 488-502.

[5] C. G. Bochet, Synlett 2004, 13, 2268-2274.

[6] M. C. Pirrung, V. S. Rana in Dynamic Studies in Biology: Phototriggers, Photoswitches, and Caged Compounds (Eds.: M. Goeldner, R. S. Givens), Wiley, New York, 2005, 341-368.

[7] J. A. McCray, D. R. Trentham, Annu. Rev. Biophys. Biophys. Chem. 1989, 18, 239-270.

[8] V. Hagen, B. Dekowski, N. Kotzur, R. Lechler, B. Wiesner, B. Briand, M. Beyermann, Chem. Eur. J. 2008, 14, 1621-1627.

[9] R. J. Lipshutz, S. P. A. Fodor, T. R. Gingeras, D. J. Lockhart, Nat. Genet. 1999, 21, 20-24.

[10] M. C. Pirrung, Angew. Chem. 2002, 114, 1326-1341; Angew. Chem. Int. Ed. 2002, 41, 1276-1289.

[11] For an overview, see: Nat. Genet. Suppl. 1999, 21, 1-60.

[12] D. G. Wang, J.-B. Fan, C.-J. Siao, A. Berno, P. Young, R. Sapolsky, G. Ghandour, N. Perkins, E. Winchester, J. Spencer, L. Kruglyak, L. Stein, L. Hsie, T. Topaloglou, E. Hubbell, E. Robinson, M. Mittmann, M. S. Morris, N. Shen, D. Kilburn, J. Rioux, C. Nusbaum, S. Rozen, T. J. Hudson, R. Lipshutz, M. Chee, E. S. Lander, Science 1998, 280, 1077-1082.

[13] D. J. Lockhart, E. A. Winzeler, Nature 2000, 405, 827-836.
[14] DNA Microarrays: A Molecular Cloning Manual (Eds.: D. Bowtell, J. Sambrook), Cold Spring Harbor Laboratory Press, Cold Spring Harbor, NY, 2003

[15] G. H. McGall, A. D. Barone, M. Diggelsmann, S. P. A. Fodor, E. Gentalen, N. Ngo, J. Am. Chem. Soc. 1997, 119, 5081-5090.

[16] A. C. Pease, D. Solas, E. J. Sullivan, M. T. Cronin, C. P. Holmes, S. P. A. Fodor, Proc. Natl. Acad. Sci. USA 1994, 91, 5022-5026.

[17] F. Bley, K. Schaper, H. Görner, Photochem. Photobiol. 2008, 84, $162-171$.

[18] A. Hasan, K.-P. Stengele, H. Giegrich, P. Cornwell, K. R. Isham, R. A. Sachleben, W. Pfleiderer, R. S. Foote, Tetrahedron 1997, 53 4247-4264.

[19] H. Giegrich, S. Eisele-Bühler, C. Hermann, E. Kvasyuk, R. Charubala, W. Pfleiderer, Nucleosides Nucleotides 1998, 17, 1987-1996.

[20] S. Bühler, I. Lagoja, H. Giegrich, K.-P. Stengele, W. Pfleiderer, Helv. Chim. Acta 2004, 87, 620-659.

[21] L. Kröck, A. Heckel, Angew. Chem. 2005, 117, 475-477; Angew. Chem. Int. Ed. 2005, 44, 471-473.

[22] S. Walbert, W. Pfleiderer, U. E. Steiner, Helv. Chim. Acta 2001, 84 , $1601-1611$.

[23] M. Beier, J. D. Hoheisel, Nucleic Acids Res. 2000, 28, e11, i-vi.

[24] J. D. Hoheisel, F. Diehl, M. Scheideler, N. Hauser, V. Aign, S. Matysiak, M. Beier in Novel Approaches in Biosensors and Rapid Diagnostic Assays (Eds.: Z. Liron, A. Brohmberg, M. Fisher), Kluwer Academic/Plenum Publishers, London, 2001, 165-172.

[25] D. Wöll, S. Walbert, K.-P. Stengele, T. J. Albert, T. Richmond, J. Norton, M. Singer, R. D. Green, W. Pfleiderer, U. E. Steiner, Helv. Chim. Acta 2004, 87, 28-45.

[26] U. E. Steiner, D. Wöll, (Universität Konstanz), DE 10315772(A1), WO 2004089529, 2004; [Chem. Abstr. 2004, 141, 366034]

[27] G. Papageorgiou, D. Ogden, E. T. Corrie, J. Org. Chem. 2004, 69, $7228-7233$.

[28] G. Papageorgiou, M. Lukeman, P. Wan, J. E. T. Corrie, Photochem. Photobiol. Sci. 2004, 3, 366-373.

[29] J. Smirnova, D. Wöll, W. Pfleiderer, U. E. Steiner, Helv. Chim. Acta 2005, 88, 891-904.

[30] D. Wöll, J. Smirnova, W. Pfleiderer, U. E. Steiner, Angew. Chem. 2006, 118, 3042-3045; Angew. Chem. Int. Ed. 2006, 45, 2975-2978.

[31] D. Wöll, S. Laimgruber, M. Galetskaya, J. Smirnova, W. Pfleiderer, B. Heinz, P. Gilch, U. E. Steiner, J. Am. Chem. Soc. 2007, 129, $12148-12158$

[32] H. Giegrich, PhD thesis, Universität Konstanz 1996.

[33] W. Bannwarth, A. Trzeciak, Helv. Chim. Acta 1987, 70, 175-186.

[34] G. Gauglitz, J. Photochem. 1976, 5, 41-47. 